\title{
The behaviour of copper anodes in aqueous thiourea-containing sulphuric acid solutions. Open circuit potentials and electrochemical kinetics
}

\author{
A.E. Bolzán *, I.B. Wakenge ${ }^{1}$, R.C.V. Piatti, R.C. Salvarezza, A.J. Arvia \\ Instituto de Investigaciones Fisicoquímícas Teóricas y Aplicadas (INIFTA) (UNLP, CONICET, CICPBA), Facultad de Ciencias Exactas, \\ Universidad Nacional de la Plata, Sucursal 4, Casilla de Correo 16, 1900 La Plata, Argentina
}

Received 10 July 2000; received in revised form 14 September 2000; accepted 19 October 2000

\begin{abstract}
The electrochemical behaviour of copper anodes in aqueous thiourea (TU)-containing sulphuric acid was followed from open circuit potential measurements, voltammetry and rotating disk and ring-disk electrode data. The open circuit potential of copper is controlled by equilibria involving different $\mathrm{Cu}(\mathrm{I})-\mathrm{TU}$ complex species. The thiourea electro-oxidation which yields formamidine disulphide and $\mathrm{Cu}(\mathrm{I})-\mathrm{TU}$ complex species can be described as a process under intermediate kinetics taking place on a partially blocked copper anode. The degree of copper surface coverage and the type of predominant adsorbate depend on the concentration of thiourea and applied electric potential. Depending on the potential range adsorbates can be formed directly from either a strong TU-copper interaction or a relatively weaker formamidine disulphide interaction. The passivating layer can be related to the formation of polymer-like $\mathrm{Cu}(\mathrm{I})-\mathrm{TU}$ layers and residues resulting both from thiourea and formamidine disulphide electro-oxidation. A previously proposed complex reaction pathway can explain the general behaviour of these systems, including adsorbate formation and the influence of the electrolyte solution constituents. (c) 2001 Elsevier Science B.V. All rights reserved.
\end{abstract}

Keywords: Copper anodes; Thiourea adsorption; Copper electro-oxidation; Formamidine disulphide; Thiourea electro-oxidation

\section{Introduction}

A large number of publications have dealt with the effect of thiourea (TU) on both the electrocrystallisation and electrodissolution of copper in aqueous environments $[1-10]$. In the presence of $\mathrm{TU}$, these processes become relatively complex by the concurrence of electrochemical reactions that are specific for $\mathrm{TU}$, and chemical reactions between TU and copper ions [11]. The electro-oxidation of TU to formamidine disulphide, $\left(\mathrm{H}_{2} \mathrm{~N}\right)_{2}(\mathrm{HN})_{2} \mathrm{C}_{2} \mathrm{~S}_{2}$ (FDS), occurs at a potential lower than the threshold potential for copper electrodissolution in aqueous solutions [12]. Otherwise, FDS is also formed from the redox reaction between $\mathrm{TU}$ and $\mathrm{Cu}$ (II) ions in solution [13], yielding different

\footnotetext{
* Corresponding author. Fax: + 54-221-4254642.

E-mail address: aebolzan@inifta.unlp.edu.ar (A.E. Bolzán).

${ }^{1}$ On leave from Université de Kinshasa, Faculté des Sciences, Département de Chimie, Kinshasa XI, République Démocratique du Congo.
}

$\mathrm{Cu}(\mathrm{I})-\mathrm{TU}$ complex ions such as $\left[\mathrm{Cu}_{x}(\mathrm{TU})_{y}\right]^{x+}$ cations, their stoichiometries depending on the $\mathrm{Cu}(\mathrm{II})-\mathrm{TU}$ concentration ratio and the nature of anions present in the solution $[14,15]$. In fact, a number of $\mathrm{Cu}(\mathrm{I})-\mathrm{TU}$ complexes have been recrystallised from acid copper sulphate and TU solutions [15]. Moreover, FDS is also capable of complexation and undergoes protonation [13]. In acidic solutions TU may undergo polycondensation to polythiourets, as concluded from the linear increase in polymer concentration with time and the reversibility of polymerisation [16].

A strong chemisorptive interaction of TU with copper has been concluded from electroreflectance spectra [16]. Recent STM imaging data of TU adsorbates on fcc metals such as Au(111) have shown that metal-TU interactions produce different potential-dependent adsorbate patterns with half-life times of the order of minutes [17]. At $E<E_{\mathrm{Cu}-\mathrm{Cu}(\mathrm{II})}^{\mathrm{r}}$, where $E_{\mathrm{Cu}-\mathrm{Cu}(\mathrm{II})}^{\mathrm{r}}$ is the reversible potential of the $\mathrm{Cu}(0)-\mathrm{Cu}(\mathrm{II})$ redox couple in the solution, these adsorbates may exist either as proto- 
nated TU, or as FDS or S adsorbed on copper [17]. Furthermore, a high degree of surface coverage by TU has been determined from open circuit potentials using the underpotential deposition of thallium as a test reaction [18]. At $E>E_{\mathrm{Cu}-\mathrm{Cu}(\mathrm{II})}^{\mathrm{r}}$ it has been found that the electro-oxidation of TU and FDS yields a variety of products such as $\mathrm{S}-$ and $\mathrm{CN}$-containing species, $\mathrm{NH}_{4}^{+}$, $\mathrm{CO}_{2}$ and $\mathrm{H}_{2} \mathrm{SO}_{4}$, their relative contributions depending on the experimental conditions [19].

This work reports reactions on polycrystalline copper electrodes in several aqueous TU- and FDS-containing $0.5 \mathrm{M}$ sulphuric acid solutions, including open circuit potential $\left(E_{\mathrm{oc}}\right)$ measurements. For $E>E_{\mathrm{oc}}$, the anodic reactions can be interpreted by a complex reaction pathway in which the electrochemistry of copper and the chemistry of TU in the presence of $\mathrm{Cu}$ (II) ions in the solution are considered. The proposed mechanism is useful for a better understanding of the influence of additives on copper corrosion inhibition and the role played by TU and its byproducts from electrochemical and chemical reactions in technical aqueous TU-containing copper plating baths.

\section{Experimental}

A number of experiments were made in a conventional glass-made three-electrode cell utilising electrorefined copper wires (diameter $0.5 \mathrm{~mm}$, geometric area ca. $0.4 \mathrm{~cm}^{2}$ ) as working electrodes. Each working

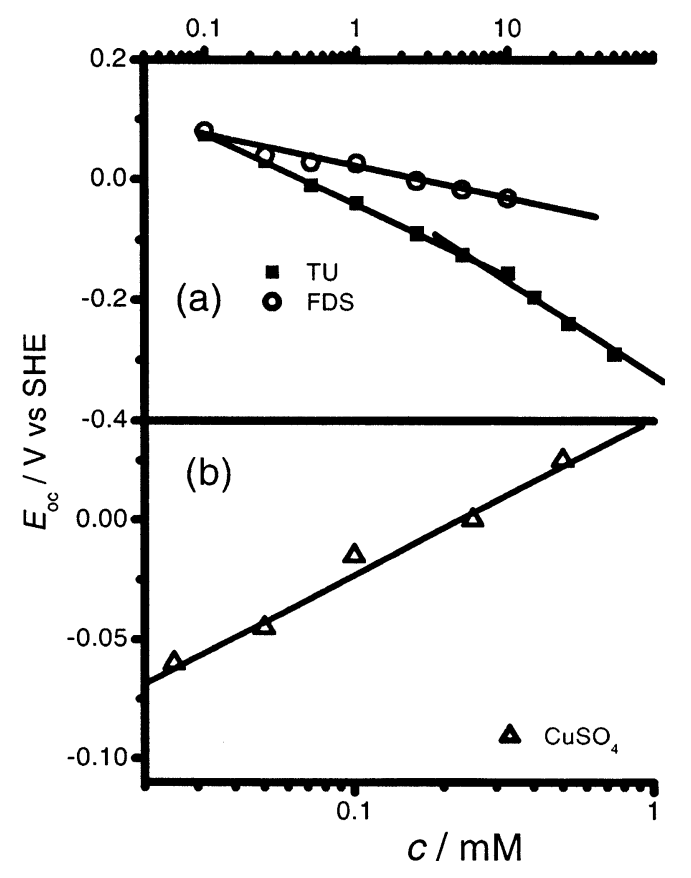

Fig. 1. (a) $E_{\mathrm{oc}}$ vs $c_{\mathrm{TU}}$ and $E_{\mathrm{oc}}$ vs $c_{\mathrm{FDS}}$ plots: (ם) $x \mathrm{mM} \mathrm{TU}+$ aqueous $0.5 \mathrm{M}$ sulphuric acid; $(\bigcirc) x \mathrm{mM}$ FDS $+0.5 \mathrm{M}$ aqueous sulphuric acid; and (b) $E_{\mathrm{oc}}$ vs $c_{\mathrm{CuSO}_{4}}$ plot. $1 \mathrm{mM} \mathrm{TU}+x \mathrm{mM}$ copper sulphate + aqueous $0.5 \mathrm{M}$ sulphuric acid, $298 \mathrm{~K}$. electrode was first electropolished in aqueous concentrated phosphoric acid [20], and subsequently immersed in aqueous concentrated sulphuric acid for $60 \mathrm{~s}$. This treatment provided a reproducible electrode surface.

Runs were also made using a rotating copper disk (RDE, type ED $10 \mathrm{~K}$ Tacussel) and a ring-disk (RRDE, type EAD $10 \mathrm{~K}$ Tacussel) electrode, consisting of a copper-disk/platinum-ring electrode $0.12 \mathrm{~cm}^{2}$ in geometric area, and collection efficiency $N=0.24$. The RDE and RRDE rotation speed $(\omega)$ was varied between 500 and $7000 \mathrm{rpm}$. Measurements were performed using a type BI-PAD Tacussel bipotentiostat.

In all cases, the counterelectrode was a large platinum sheet $\left(2 \mathrm{~cm}^{2}\right.$ apparent area). Potentials $(E)$ were measured against a saturated calomel electrode (SCE), although in the text they are given on the standard hydrogen electrode (SHE) scale.

Working solutions were prepared from Fluka, puriss. p.a. chemicals, 97\% Merck, p.a. sulphuric acid and Milli-Q* water. They were kept under nitrogen saturation before and during the experiment.

The influence of TU, FDS, copper ions in solution and $\mathrm{pH}$ on the copper electrode open circuit potential $\left(E_{\mathrm{oc}}\right)$ was determined using the following solutions: aqueous $0.5 \mathrm{M}$ sulphuric acid $+x \mathrm{mM}$ TU $(0.1 \leq x \leq$ 50); $0.5 \mathrm{M}$ sulphuric acid $+1 \mathrm{mM} \mathrm{TU}+x \mathrm{mM}$ copper sulphate $(0 \leq x \leq 0.5) ; 0.5 \mathrm{M}$ sulphuric acid $+x \mathrm{mM}$ FDS $(0.1 \leq x \leq 10) ; 0.5$ M sulphuric acid $+1 \mathrm{mM}$ $\mathrm{TU}+x \mathrm{mM}$ FDS $(0.1 \leq x \leq 10) ; x$ M sulphuric acid + $(0.5-x) \mathrm{M}$ sodium sulphate $+1 \mathrm{mM} \mathrm{TU} ; x \mathrm{M}$ sulphuric acid $+(0.5-x)$ M sodium sulphate $+1 \mathrm{mM}$ FDS and $x$ M sulphuric acid $+(0.5-x)$ M sodium sulphate $+0.1 \mathrm{mM}$ copper sulphate. As reported in the text, values of $E_{\mathrm{oc}}$ were stable for at least $30 \mathrm{~min}$.

Conventional voltammetry was run with either aqueous TU- or FDS-containing $0.5 \mathrm{M}$ sulphuric acid utilising a conventional potentiostat and waveform generator.

All runs were made at $298 \mathrm{~K}$.

\section{Results}

\subsection{Open circuit potentials}

In the range $0.1 \mathrm{mM} \leq c_{\mathrm{TU}} \leq 50 \mathrm{mM}$, the value of $E_{\text {oc }}$ for copper in aqueous TU-containing $0.5 \mathrm{M}$ sulphuric acid decreases as the concentration of $\mathrm{TU}\left(c_{\mathrm{TU}}\right)$ is increased. The $E_{\mathrm{oc}}$ vs $\log c_{\mathrm{TU}}$ plot shows two linear regions with slopes approaching $-0.118 \pm 0.005$ $\mathrm{V}$ decade $^{-1}$ for $0.1 \mathrm{mM} \leq c_{\mathrm{TU}} \leq 10 \quad \mathrm{mM}$, and $-0.180 \pm 0.005 \mathrm{~V} \mathrm{decade}^{-1}$ for $10 \mathrm{mM} \leq c_{\mathrm{TU}} \leq 50$ $\mathrm{mM}$ (Fig. 1a). The crossing point lies at $E_{\mathrm{oc}} \simeq-0.17 \mathrm{~V}$ and $c_{\mathrm{TU}} \simeq 6 \mathrm{mM}$.

As FDS participates in those equilibria related to the TU-copper system [1], it was worth establishing the 

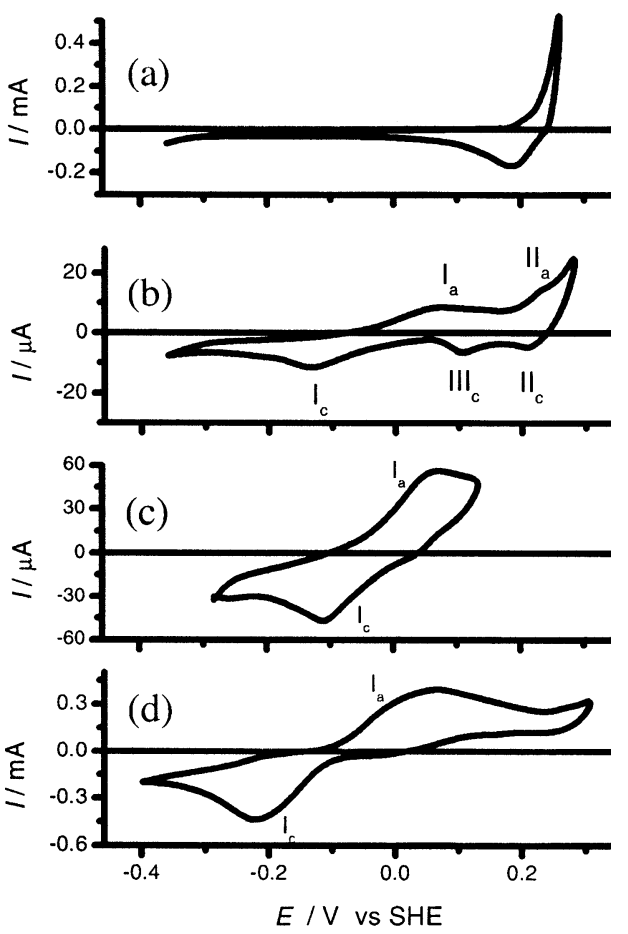

Fig. 2. Cyclic voltammograms for copper in aqueous $0.5 \mathrm{M}$ sulphuric acid with different concentrations of TU: (a) $0 \mathrm{mM}$; (b) $0.5 \mathrm{mM}$; (c) $1 \mathrm{mM}$; (d) $10 \mathrm{mM}, v=0.05 \mathrm{~V} \mathrm{~s}^{-1}$ at $298 \mathrm{~K}$.

influence of $c_{\mathrm{FDS}}$ on $E_{\mathrm{oc}}$ both in the presence and absence of TU. For copper in aqueous FDS-containing $0.5 \mathrm{M}$ sulphuric acid, the value of $E_{\mathrm{oc}}$ decreases linearly with $\log c_{\text {FDs }}$. The slope of this line approaches -0.059 $\mathrm{V}$ decade $^{-1}$ for $0.1 \mathrm{mM} \leq c_{\mathrm{FDS}} \leq 10 \mathrm{mM}$. For $c_{\mathrm{FDS}}>$ $10 \mathrm{mM}$, the determination of open circuit potentials is limited by the solubility of FDS in the acid solution. It should be noted that for $c_{\mathrm{TU}} \simeq c_{\mathrm{FDS}}<0.02 \mathrm{mM}$, both $E_{\mathrm{oc}}$ vs $\log c_{\mathrm{TU}}$ and $E_{\mathrm{oc}}$ vs $\log c_{\mathrm{FDS}}$ linear plots tend to coincide. Otherwise, for copper in $1 \mathrm{mM} \mathrm{TU}+x \mathrm{mM}$ FDS $(0.1 \leq x \leq 10)+0.5 \mathrm{M}$ sulphuric acid, the value of $E_{\mathrm{oc}}$ remains practically constant. These results show that the value of $E_{\mathrm{oc}}$ for copper immersed in these solutions is determined by the presence of TU, irrespective of the presence of FDS in the solution. This fact strongly suggests that the $\mathrm{Cu}-\mathrm{TU}$ interaction becomes stronger than the $\mathrm{Cu}-\mathrm{FDS}$ interactions, in agreement with energy calculations made for the metal surfacethiol and the metal surface-dithiol [21].

In copper sulphate $\left(0.025 \mathrm{mM} \leq c_{\mathrm{CuSO}_{4}} \leq\right.$ $0.5 \mathrm{mM})+1 \mathrm{mM} \mathrm{TU}+$ aqueous $0.5 \mathrm{M}$ sulphuric acid, $E_{\text {oc }}$ increases almost linearly with $\log c_{\mathrm{CuSO}_{4}}$. The slope of the straight line is $0.060 \pm 0.005 \mathrm{~V} \mathrm{decade}^{-1}$ (Fig. $1 b)$. Finally, the value of $E_{\mathrm{oc}}$ becomes $\mathrm{pH}$-independent in the range $0.9 \leq \mathrm{pH} \leq 5.8$ for both TU- and FDScontaining solutions. This dependence of $E_{\text {oc }}$ on the solution composition can be analysed considering those chemical reactions and equilibria in which aqueous $\mathrm{Cu}(\mathrm{I})-\mathrm{TU}$ complex species are involved [22], as is discussed later. The stoichiometry of these complex species depends on the composition of the solution, particularly on the initial $\mathrm{Cu}(\mathrm{II})-\mathrm{TU}$ molar concentration ratio $[14,15]$.

\subsection{Cyclic voltammetry}

Cyclic voltammograms of copper in aqueous TUcontaining $0.5 \mathrm{M}$ sulphuric acid run at $v=0.05 \mathrm{~V} \mathrm{~s}^{-1}$ (Fig. 2a) from -0.35 to $0.26 \mathrm{~V}$ exhibit a flat current profile, with an increasing anodic faradaic current starting from ca. $0.19 \mathrm{~V}$ in the positive direction due to the commencement of copper electrodissolution. This process involves a first positive hump related to the $\mathrm{Cu}(0) \rightleftharpoons \mathrm{Cu}(\mathrm{I})+\mathrm{e}^{-}$reaction and a second abrupt increase in anodic current due to the $\mathrm{Cu}(0) \rightleftharpoons \mathrm{Cu}(\mathrm{II})+$ $2 \mathrm{e}^{-}$overall reaction. The subsequent reverse scan shows a negative peak at ca. $0.19 \mathrm{~V}$ due to the electrodeposition of $\mathrm{Cu}(\mathrm{II})$ ions formed in the preceding potential scan. This process is associated with the cathodic current plateau that extends in the range 0.05 $\mathrm{V} \leq E \leq-0.25 \mathrm{~V}$. Finally, starting from $-0.25 \mathrm{~V}$ in the negative direction, the cathodic current increases steadily due to the contribution of the hydrogen evolution reaction (her) on copper.

For copper in aqueous $0.5 \mathrm{mM} \mathrm{TU}+0.5 \mathrm{M}$ sulphuric acid the cyclic voltammogram run at $0.05 \mathrm{~V} \mathrm{~s}^{-1}$ between -0.35 and $0.28 \mathrm{~V}$ (Fig. 2b) exhibits two positive $\left(\mathrm{I}_{\mathrm{a}}\right.$ and $\left.\mathrm{II}_{\mathrm{a}}\right)$ and three negative $\left(\mathrm{I}_{\mathrm{c}}, \mathrm{II}_{\mathrm{c}}\right.$ and $\left.\mathrm{III}_{\mathrm{c}}\right)$ current peaks. Conjugated peaks $I_{a}$ and $I_{c}$ are more clearly defined by potential scanning between -0.3 and $0.15 \mathrm{~V}$, at $0.01 \mathrm{~V} \mathrm{~s}^{-1}$, in $1 \mathrm{mM} \mathrm{TU}+0.5 \mathrm{M}$ sulphuric acid (Fig. 2c). The pair of peaks $\mathrm{II}_{\mathrm{a}}$ and $\mathrm{II}_{\mathrm{c}}$ appears to be related to a second conjugated electrochemical reaction. Peak $\mathrm{III}_{\mathrm{a}}$ which can be correlated to that observed in aqueous TU-free $0.5 \mathrm{M}$ sulphuric acid (Fig. 2a), corresponds to copper electrodeposition from a very low concentration of $\mathrm{Cu}(\mathrm{II})$ ions remaining in the solution after copper electro-oxidation has occurred. As $c_{\mathrm{TU}}$ is increased to $10 \mathrm{mM}$, peaks $\mathrm{I}_{\mathrm{a}}$ and $\mathrm{II}_{\mathrm{c}}$ are strongly depressed, whereas peak $\mathrm{III}_{\mathrm{c}}$ is no longer observed. In this case, an anodic current plateau covering the range $0.1-0.25 \mathrm{~V}$ is recorded (Fig. 2d).

The heights of peaks $\mathrm{I}_{\mathrm{a}}, \mathrm{II}_{\mathrm{c}}$ and $\mathrm{III}_{\mathrm{c}}$ depend linearly on $v^{1 / 2}$ (Fig. 3). Otherwise, no clearcut linear dependence of peak potentials $\left(E_{\mathrm{p}, \mathrm{a}}\right.$ and $\left.E_{\mathrm{p}, \mathrm{c}}\right)$ on either $v$ or $\log v$ was observed, as expected for a simple, either reversible or irreversible, electrochemical reaction under diffusion control [23].

The value of the $I_{\mathrm{p}, \mathrm{a}}$, (the height of peak $\mathrm{I}_{\mathrm{a}}$ ) vs $v^{1 / 2}$ plot, at constant $c_{\mathrm{TU}}$, approaches a linear relationship only for $v<0.01 \mathrm{~V} \mathrm{~s}^{-1}$, whereas an increasing deviation from the linearity expected for a simple diffusion controlled electrochemical reaction [23] is found for $v>0.1 \mathrm{~V} \mathrm{~s}^{-1}$ (Fig. 4). From these plots, it also results that the $I_{\mathrm{p}, \mathrm{a}} / I_{\mathrm{p}, \mathrm{a}}^{1}$ ratio from cyclic voltammograms, 
where $I_{\mathrm{p}, \mathrm{a}}^{1}$ is the value of $I_{\mathrm{p}, \mathrm{a}}$ read from the linear plot, is independent of $v$. These facts suggest that on increasing $c_{\mathrm{TU}}$ an accumulation of adsorbed TU residues on the copper anode is produced, which would lead to a decrease in the effective area of the copper anode. Therefore, the deviation of the $I_{\mathrm{p}} / v^{1 / 2}$ plot from linearity could be assigned to a surface blockage by TU and

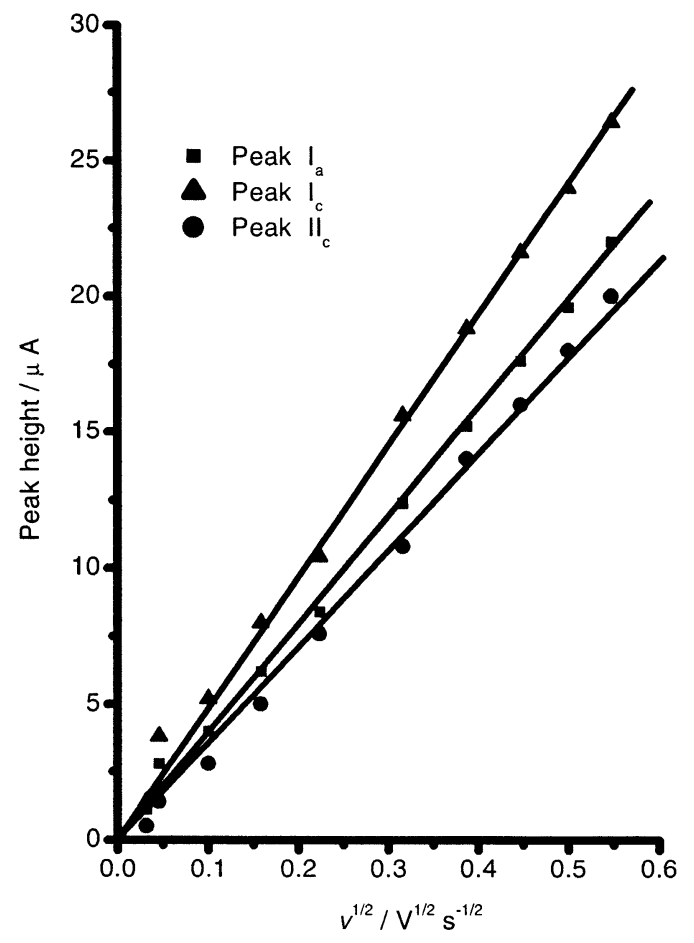

Fig. 3. Voltammetric peak heights vs $v^{1 / 2}$ plots; $0.5 \mathrm{mM} \mathrm{TU}+$ aqueous $0.5 \mathrm{M}$ sulphuric acid, $298 \mathrm{~K}$.

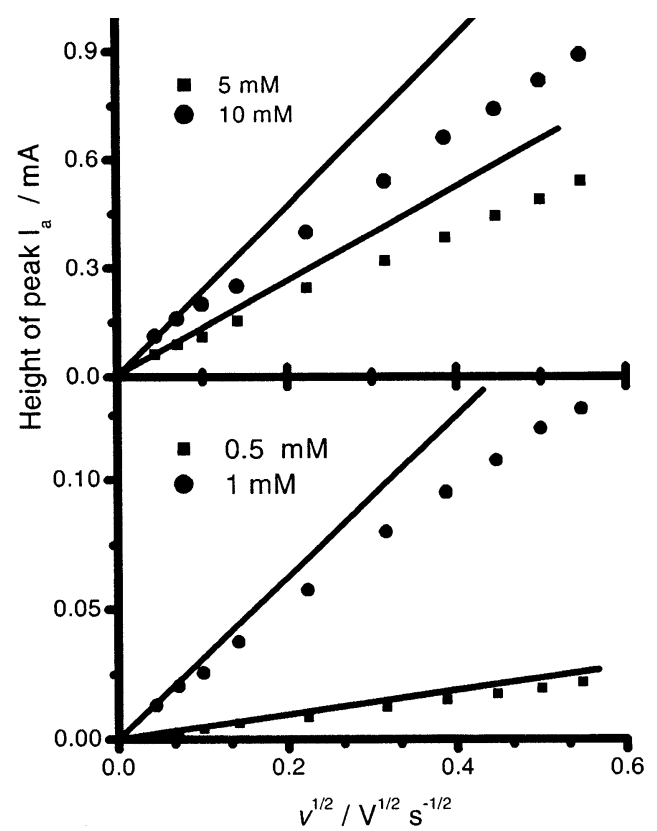

Fig. 4. Height of peak $\mathrm{I}_{\mathrm{a}}$ vs $v^{1 / 2}$ plots for different $c_{\mathrm{TU}} ; x \mathrm{mM}$ $\mathrm{TU}+$ aqueous $0.5 \mathrm{M}$ sulphuric acid, $298 \mathrm{~K}$.

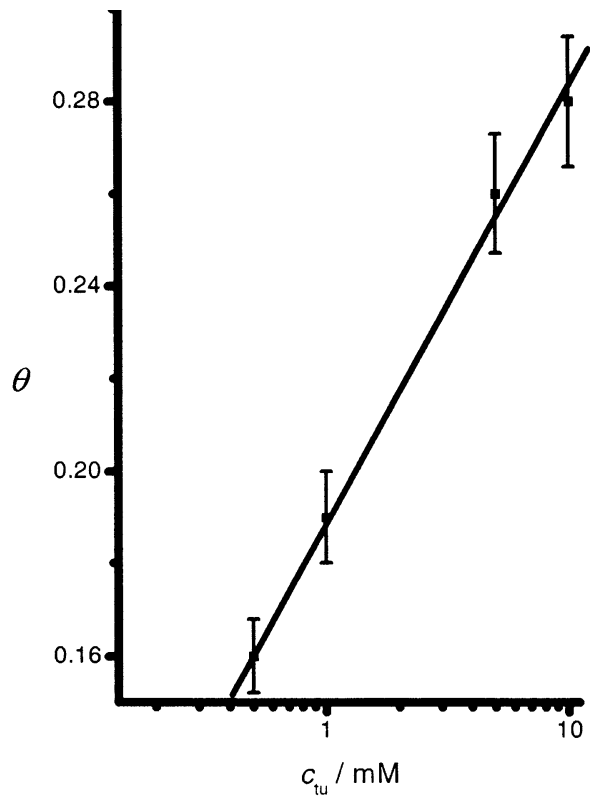

Fig. 5. Plot of $\theta$ vs $\log c_{\mathrm{TU}}$ resulting from cyclic voltammetry run at $v=0.15 \mathrm{~V} \mathrm{~s}^{-1}$ (Fig. 4).

TU-derivative adsorbates. Accordingly, the degree of surface coverage $(\theta)$ by adsorbates can be estimated as $\theta=1-I_{\mathrm{p}, \mathrm{a}} / I_{\mathrm{p}, \mathrm{a}}^{1}$, the value of $\theta$ increasing linearly with $\log c_{\mathrm{TU}}$ (Fig. 5).

\subsection{Adsorbate formation from $T U$ on copper}

The formation of TU adsorbates on copper has been demonstrated by several procedures [16,18,24-26]. These adsorbates play a definite role in the electrochemical reactions of copper in aqueous TU-containing solutions.

The presence of TU adsorbates on copper, as well as their electro-oxidation potential window, was confirmed by the underpotential deposition (upd) of thallium on copper as a test reaction. A blank voltammogram for copper in aqueous $0.1 \mathrm{mM}$ thallium sulphate $+0.5 \mathrm{M}$ sulphuric acid (Fig. 6) run from $01 \mathrm{~V}$ in the negative direction, i.e. in the potential range where alloying effects are negligible [27-30], exhibits a negative hump at ca. $-0.32 \mathrm{~V}$ related to thallium upd. This hump overlaps, to some extent, the cathodic current baseline related to the her, whereas in the reverse scan, a welldefined single positive peak at ca. $-025 \mathrm{~V}$, due to the anodic stripping of thallium, can be observed. The charge density resulting from the positive peak is 0.15 $\mathrm{mC} \mathrm{cm}-2$, a figure which is about one-half of that expected for 1.5 monolayers of thallium [29]. It has been demonstrated that this charge density depends on whether the copper surface has been subjected to a mechanical or an electropolishing electrode pretreatment [29]. Correspondingly, either single or multiple peaks for thallium upd on copper are observed [18]. 
Otherwise, when the copper electrode has been previously immersed in aqueous $0.5 \mathrm{mM} \mathrm{TU}+0.5 \mathrm{M}$ sulphuric acid for $30 \mathrm{~s}$ at $E=-0.35 \mathrm{~V}$, the subsequent voltammogram in $0.1 \mathrm{mM}$ thallium sulphate $+0.5 \mathrm{M}$ sulphuric acid shows a strong decrease both in thallium upd and anodic stripping charges. After deconvolution from the contribution of her the thallium stripping charge is $0.02 \mathrm{mC} \mathrm{cm}^{-2}$. Accordingly, from the charge

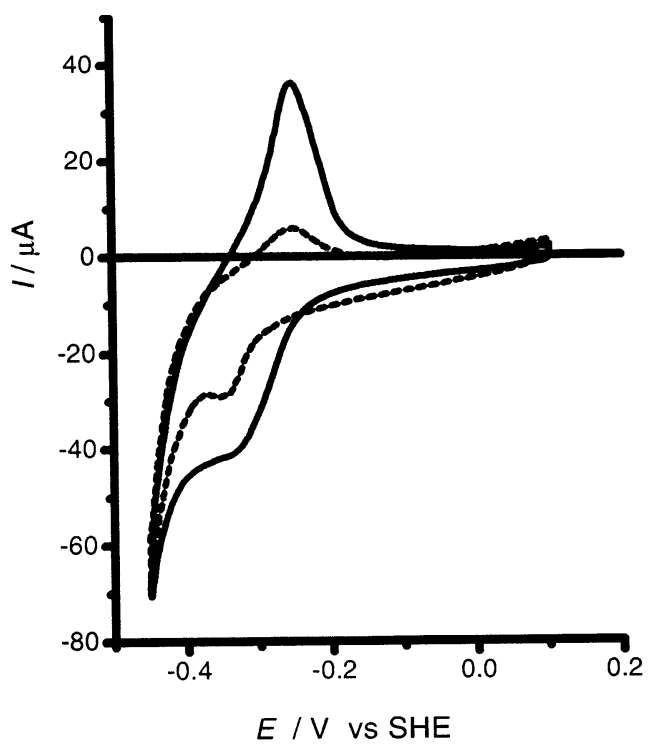

Fig. 6. Voltammograms of copper in aqueous $0.1 \mathrm{mM}$ thallium sulphate $+0.5 \mathrm{M}$ sulphuric acid; blank (full trace). After immersion at $-0.45 \mathrm{~V}$ for $30 \mathrm{~s}$ in $0.5 \mathrm{mM} \mathrm{TU}+$ aqueous $0.5 \mathrm{M}$ sulphuric acid (dotted trace). Electrode area $0.4 \mathrm{~cm}^{2}, v=0.05 \mathrm{~V} \mathrm{~s}^{-1}$ at $298 \mathrm{~K}$.

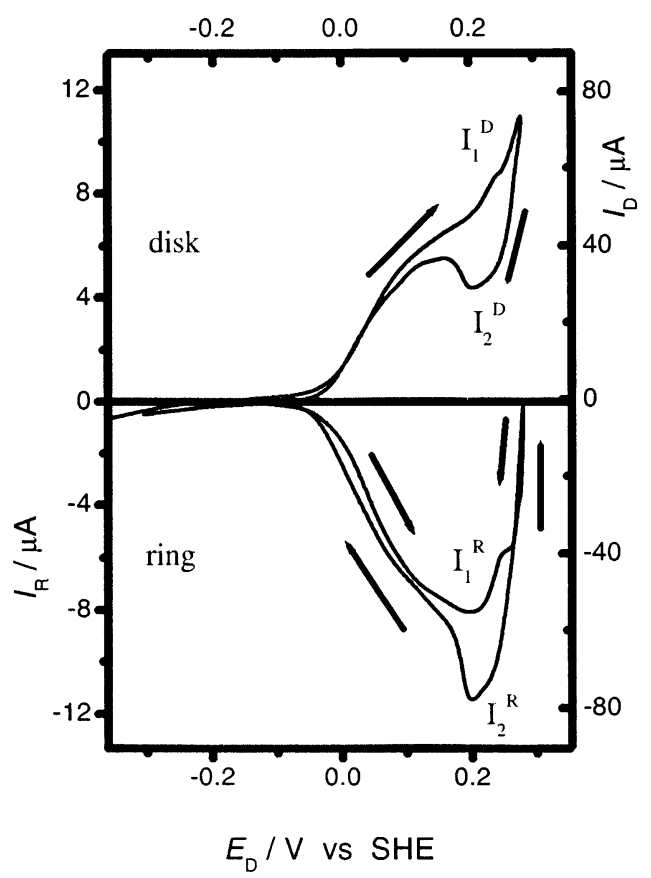

Fig. 7. Rotating ring disk voltammograms; $0.5 \mathrm{mM} \mathrm{TU}+$ aqueous $0.5 \mathrm{M}$ sulphuric acid. $E_{\mathrm{R}}=-0.26 \mathrm{~V} ; \omega=2000 \mathrm{rpm} ; v=0.05 \mathrm{~V} \mathrm{~s}^{-1}$ at $298 \mathrm{~K}$. ratio of this experiment and that of the blank, the copper surface coverage by TU adsorbates was estimated as $85 \%$, a figure which is comparable to that found for TU adsorbates on Au(111) from STM imaging [17].

Finally, the voltammogram of TU adsorbates on copper run in aqueous $0.5 \mathrm{M}$ sulphuric acid between -0.3 and $0.17 \mathrm{~V}$, i.e. a potential window between the her and the copper electrodissolution threshold potential, showed no electro-oxidation current attributable to TU adsorbates. Therefore, it appears that TU adsorbates on copper are essentially stable at potentials below the TU electro-oxidation threshold potential.

\subsection{RRDE data}

Rotating ring-disk current/potential profiles in aqueous $0.5 \mathrm{mM} \mathrm{TU}+0.5 \mathrm{M}$ sulphuric acid run in the positive potential direction between -0.36 and $0.28 \mathrm{~V}$ at $v=0.05 \mathrm{~V} \mathrm{~s}^{-1}$ and $\omega=2000 \mathrm{rpm}$ (Fig. 7), show a very small current both at the copper disk and platinum ring electrodes. The anodic current at the disk approaches a quasi-limiting value at $0.15 \mathrm{~V}$. At ca. $0.2 \mathrm{~V}$, the anodic current rises again showing up a small hump $\left(\mathrm{I}_{1}^{\mathrm{D}}\right)$ at ca. $0.24 \mathrm{~V}$. The reverse potential scan shows a remarkable hysteresis, i.e. first the current decreases to a minimum value at ca. $0.2 \mathrm{~V}\left(\mathrm{I}_{2}^{\mathrm{D}}\right)$, and then it increases up to a maximum. Later, the current tends to overlap the positive-going potential voltammetric scan. These results suggest that in the range $0 \mathrm{~V} \leq E_{\mathrm{D}} \leq 0.2 \mathrm{~V}$ mass transfer and surface electrochemical reactions are involved. It should be noted that for $c_{\mathrm{TU}}=0.5 \mathrm{mM}$, the decrease in $v$ from 0.05 to $0.005 \mathrm{~V} \mathrm{~s}^{-1}$ produces a strong decrease of both $\mathrm{I}_{1}^{\mathrm{D}}$ and $\mathrm{I}_{2}^{\mathrm{D}}$. Simultaneously, the cathodic current at the ring held at $E_{\mathrm{R}}=-0.26 \mathrm{~V}$ increases steadily. Subsequently, a small wave is observed and finally, the null current is attained. The reverse scan first shows a cathodic current jump followed by the appearance of peak $\mathrm{I}_{2}^{\mathrm{R}}$, and when $E_{\mathrm{D}} \simeq$ $-0.1 \mathrm{~V}$, the current decreases to zero.

Data from RRDE experiments depend on $v, \omega$ and $c_{\mathrm{TU}}$. Thus, as $c_{\mathrm{TU}}$ is increased from 0.5 to $10 \mathrm{mM}$ and $v$ is decreased from 0.05 to $0.005 \mathrm{~V} \mathrm{~s}^{-1}$, the disk voltammogram in the positive potential direction shows no peaks such as those described above for $c_{\mathrm{TU}}=0.5$ $\mathrm{mM}$; the overall voltammogram displays an anodic current plateau with a hysteresis loop (Fig. 8). Likewise, the cathodic current at the ring held at $E_{\mathrm{R}}=$ $-0.26 \mathrm{~V}$ exhibits a remarkable hysteresis with a current maximum at ca. $0.12 \mathrm{~V}$. For the reverse potential scan, the cathodic current at the ring decreases almost linearly with $E_{\mathrm{D}}$.

These results are consistent with the formation of soluble products that are electroreduced at the platinum ring held at $E_{\mathrm{R}}=-0.26 \mathrm{~V}$ during the electro-oxidation of $\mathrm{TU}$ at the copper disk electrode. The formation of 


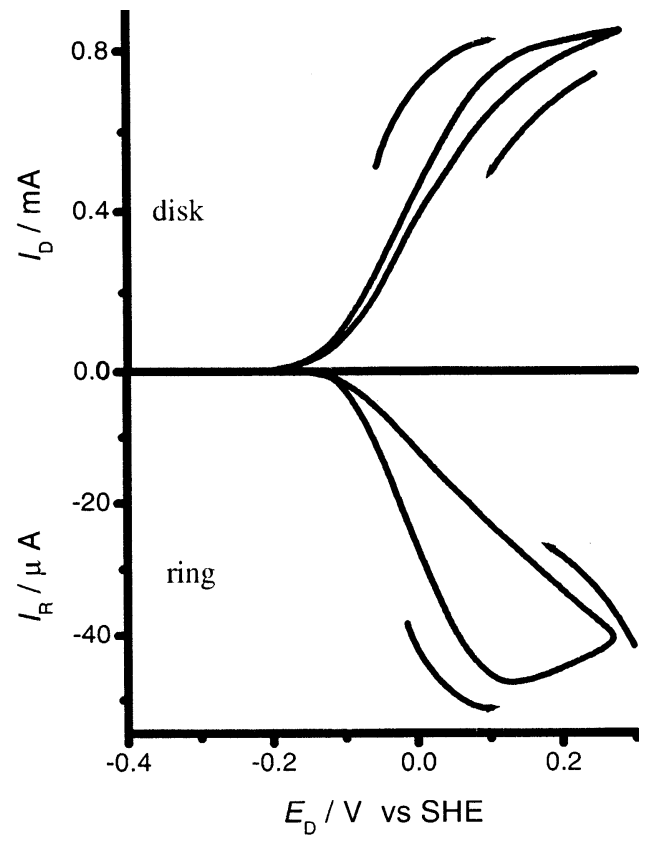

Fig. 8. Rotating ring disk voltammograms; $10 \mathrm{mM}$ TU + aqueous 0.5 $\mathrm{M}$ sulphuric acid. $E_{\mathrm{R}}=-0.26 \mathrm{~V} ; \omega=2000 \mathrm{rpm} ; v=0.005 \mathrm{~V} \mathrm{~s}^{-1}$.

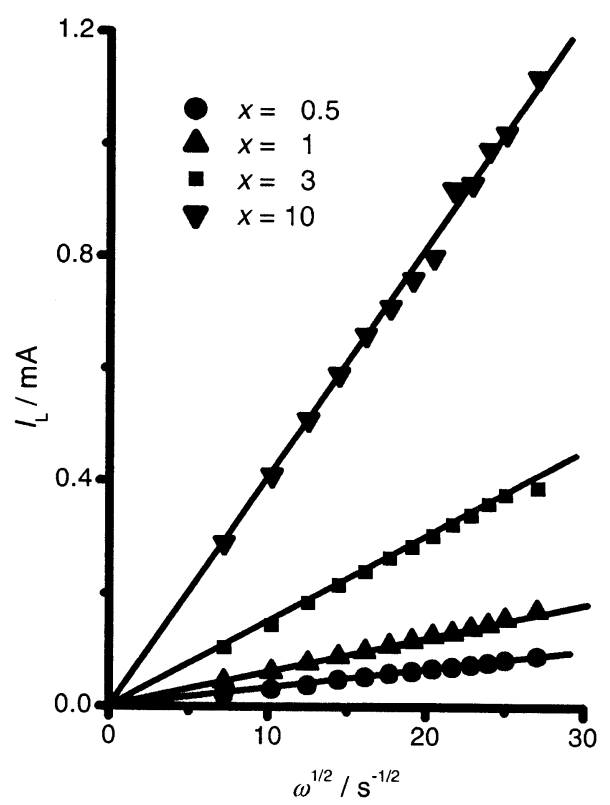

Fig. 9. Plots of $I_{\mathrm{L}}$ vs $\omega^{1 / 2}$ derived from quasi-stationary current potential curves recorded at $v=0.005 \mathrm{~V} \mathrm{~s}^{-1}$ in $x \mathrm{mM} \mathrm{TU}+$ aqueous $0.5 \mathrm{M}$ sulphuric acid at $298 \mathrm{~K}$.

soluble products appears to be gradually inhibited as $E_{\mathrm{D}}>0.2 \mathrm{~V}$, i.e. in the potential range where the electrodissolution of copper to $\mathrm{Cu}$ (II) ions in the blank is observed (Fig. 2). This inhibition is likely caused by the accumulation of insoluble $\mathrm{Cu}(\mathrm{I})$ complex species at the electrode/solution interface [18,31], although the effect tends to disappear as either $c_{\mathrm{TU}}$ is increased or $v$ is decreased, i.e. when an excess of TU is present at the reaction interface the passivating film that is formed on the anode tends to dissolve.

\subsection{RDE data}

For a copper RDE immersed in aqueous $x \mathrm{mM}$ $\mathrm{TU}+0.5 \mathrm{M}$ sulphuric acid the anodic limiting current $\left(I_{\mathrm{L}}\right)$, recorded at $v=0.005 \mathrm{~V} \mathrm{~s}^{-1}$, changes linearly with $\omega^{1 / 2}$ (Fig. 9). The slope from these plots, $\Delta I_{\mathrm{L}} / \Delta \omega^{1 / 2}$, increases with $c_{\mathrm{TU}}$ (Fig. 10), although this increase is slower than that expected from a $\Delta I_{\mathrm{L}} / \Delta \omega^{1 / 2}$ vs $c_{\mathrm{TU}}$ linear dependence. This behaviour is consistent with that already described from the voltammetric current peaks on $c_{\mathrm{TU}}$ (Fig. 4). It suggests that the mass transport-controlled anodic reaction is to some extent hindered by a progressive blockage of the electrode surface by reaction products, as $c_{\mathrm{TU}}$ is increased.

The deviation from linearity of the $\Delta I_{\mathrm{L}} / \Delta \omega^{1 / 2}$ vs $c_{\mathrm{TU}}$ plot (Fig. 10) can be related to an increase in the value of $\theta$ with $c_{\mathrm{TU}}$. Following the same assumption made for voltammetric data, for quasi-steady adsorption conditions prevailing at the RDE, values of $\theta$ were obtained from the deviation of the above-mentioned plot. In this case, the result is again that $\theta$ approaches a linear increase with $\log c_{\mathrm{TU}}$ (Fig. 10, inset). At constant $c_{\mathrm{TU}}$, the difference in the values of $\theta$ in the plots depicted in Figs. 5 and 10 (inset) is coherent with the specific conditions of each type of experiment.

The quasi-stationary current/potential curves covering the potential range $0 \mathrm{~V} \leq E_{\mathrm{D}} \leq-0.2 \mathrm{~V}$ fit the Koutecky-Levich-like plots (Fig. 11). The slope of these linear plots is almost independent of $c_{\mathrm{TU}}$, as

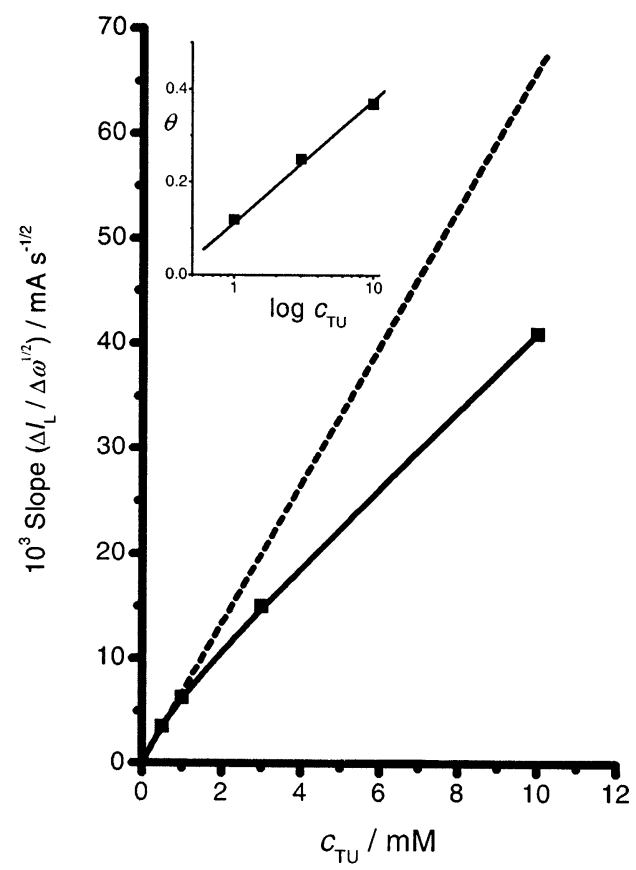

Fig. 10. Plots of $\Delta I_{\mathrm{L}} / \Delta \omega^{1 / 2}$ vs $c_{\mathrm{TU}}$ aud $\theta$ vs $\log c_{\mathrm{TU}}$. Data derived from Fig. 9. 


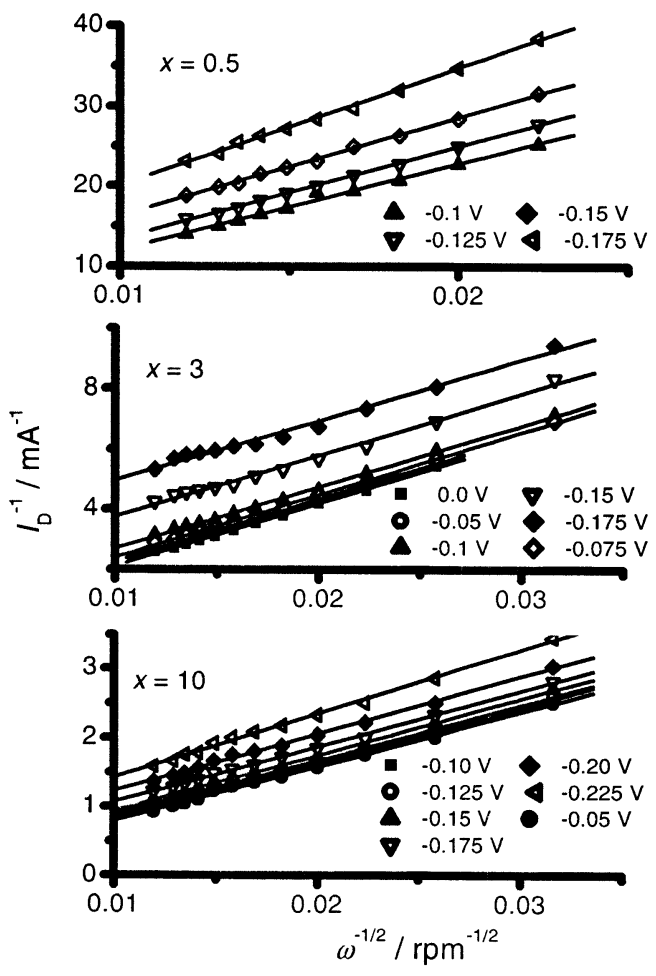

Fig. 11. Plots of $1 / I$ vs $1 / \omega^{1 / 2}$ at different $E$ derived fiom quasi-stationary curves recorded at $0.005 \mathrm{~V} \mathrm{~s}^{-1}$ in $x \mathrm{mM} \mathrm{TU}+$ aqueous 0.5 M sulphuric acid at $298 \mathrm{~K}$.

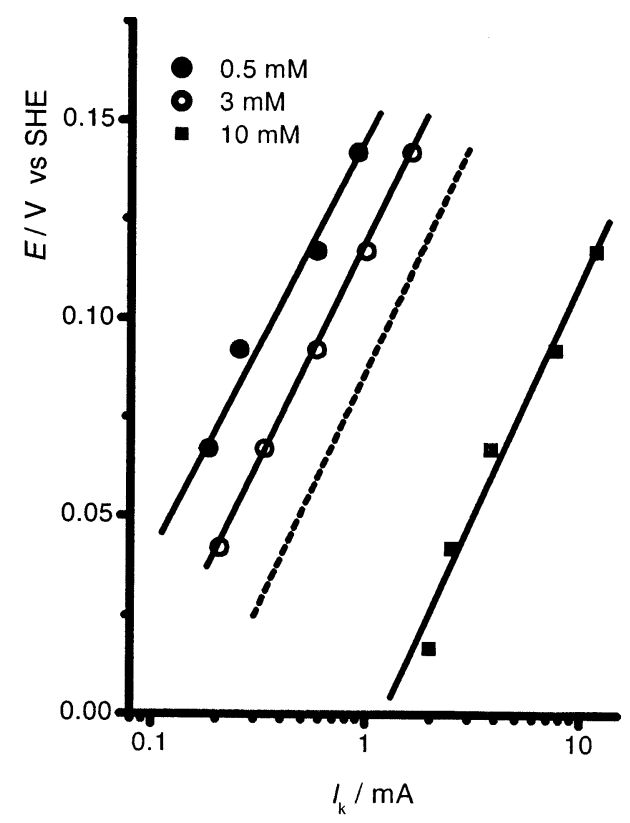

Fig. 12. Plots of $I_{\mathrm{k}}$ vs $E$ for copper in $x \mathrm{mM}$ TU + aqueous $0.5 \mathrm{M}$ sulphuric acid. Dotted line indicates the slope $0.118 \mathrm{~V} \mathrm{decade}^{-1}$.

expected for a first-order electrochemical reaction under mass transport control. The value of the ordinate for $\omega \rightarrow \infty$ provides the true kinetic current $I_{\mathrm{k}}$ for the heterogeneous electrochemical reaction. The value of $I_{\mathrm{k}}$ fits a reasonable $E_{\mathrm{D}}$ vs $\log I_{\mathrm{k}}$ linear relationship with a slope $b_{\mathrm{T}}=\Delta E_{\mathrm{D}} / \Delta \log I_{\mathrm{k}} \simeq 0.118 \mathrm{~V} \mathrm{decade}^{-1}$ (Fig. 12).

\section{Discussion}

The electrochemistry of copper in aqueous TU-containing acid solution becomes more complex than previously thought [18], particularly because only in recent years has the knowledge of these systems been enriched by the advances in the understanding of nature of ionic complexes and structures of compounds produced and recrystallised from solutions [14,15], and the stability and structure of TU and TU-derivatives adlayers [17]. In fact, the formation of rather stable complexes in aqueous TU- and $\mathrm{Cu}(\mathrm{II})$-containing acid solutions involves a number of chemical reactions and homogeneous and heterogeneous equilibria, and TU-copper and TU-derivatives-copper interactions that play an important role in dealing with both anodic and cathodic copper electrode reactions in these solutions. Therefore, for such systems, it is convenient to first review the most relevant chemical and electrochemical reactions that might be of interest for the interpretation of data presented in this work.

\subsection{Chemistry of aqueous TU-containing acid solutions}

It is well known that TU is a fairly large polarisable molecule, most likely poorly solvated in aqueous solutions, and that it exhibits acid-base properties [32]. In highly acid solutions, TU exists predominantly as a monoprotonated species $\mathrm{NH}_{2} \mathrm{CSNH}_{3}^{+}$[33]

$\left(\mathrm{H}_{2} \mathrm{~N}\right)_{2} \mathrm{CS}+\mathrm{H}^{+} \rightleftharpoons \mathrm{NH}_{2} \mathrm{CSNH}_{3}^{+}$

with a protonation constant of 1.44 at $298 \mathrm{~K}$ [34]. In aqueous $0.5 \mathrm{M}$ sulphuric acid, the fraction of protonated TU is about $2-4 \%$ [35].

Conversely, the hydrolysis of TU in aqueous solution yields urea and hydrogen sulphide [36]

$\mathrm{TU}+\mathrm{H}_{2} \mathrm{O} \rightarrow \mathrm{H}_{2} \mathrm{NCONH}_{2}+\mathrm{H}_{2} \mathrm{~S}$

Reaction (2) being favoured by the tautomeric form $\mathrm{H}_{2} \mathrm{NHNC}-\mathrm{SH}[19]$.

In acidic solutions the chemical oxidation of TU and its alkyl derivatives with hydrogen peroxide yields a mixture of ammonia, sulphur, sulphuric acid and carbon dioxide [37]. This complex process might be of interest for the electrochemical reactions on metals in aqueous TU-containing electrolyte solutions $[25,38,39]$.

As occurs for thiols [40], in acid aqueous solutions TU and FDS are involved in the redox process reaction [12]

$\mathrm{FDS}+2 \mathrm{H}^{+}+2 \mathrm{e}^{-} \rightleftharpoons 2 \mathrm{TU}$ 
where the standard potential of Reaction (3) is $E^{0}=$ $0.420 \mathrm{~V}$ (SHE) [1,41]. Reaction (3) is favoured by the deprotonation of the tautomeric form of TU.

The stabilisation of FDS depends on the electrolyte composition; FDS can be crystallised in the form of either a chlorhydrate or a sulphate. The spontaneous decomposition of FDS in acid yields different products: $\mathrm{TU}$, cyanamide and sulphur being the most important $[42,43]$. This process, which is also interesting for those reactions occurring at high positive potentials [18], can be followed by the absorption bands in the visible-UV spectra for TU at $237 \mathrm{~nm}$ and for FDS at $206 \mathrm{~nm}$ [13].

\subsection{Chemistry of $T U$ in $C U(I I)$-containing solutions}

In aqueous $\mathrm{Cu}(\mathrm{II})$ and $\mathrm{TU}$-containing solutions, $\mathrm{TU}$ is oxidised by $\mathrm{Cu}(\mathrm{II})$ ions [44] yielding FDS and $\mathrm{Cu}(\mathrm{I})-$ TU complex species [13] through a formal reaction such as

$2 \mathrm{Cu}^{2+}+4 \mathrm{TU} \rightarrow \mathrm{FDS}+2[\mathrm{Cu}(\mathrm{TU})]^{+}+2 \mathrm{H}^{+}$

where $[\mathrm{Cu}(\mathrm{TU})]^{+}$represents a primary complex ion in solution without stoichiometric specification. It has been reported that reaction (4) exhibits a polarographic anodic-cathodic wave near $0.242 \mathrm{~V}$ (SHE) [12]. The positive charge of the ionised complex has been determined using the Hittorf method [13] and its absorption spectrum characterised by a band at $340 \mathrm{~nm}$ [13]. The chemical reduction of $\mathrm{Cu}(\mathrm{II})$ ions by $\mathrm{TU}$ in solution can be followed by UV-vis spectrophotometry [45].

Although the complex ion yielded by Reaction (4) has been described as $[\mathrm{Cu}(\mathrm{TU})]^{+}\left(\log \beta_{4}=15\right.$ [46]), several stable forms of $\mathrm{Cu}(\mathrm{I})-\mathrm{TU}$ complex ions with a number of TU ligands higher than 1 were also proposed earlier [47] and later observed [14,15]. In this case, primary complex ions from reaction (4) would react further as follows:

$x[\mathrm{Cu}(\mathrm{TU})]^{+}+y \mathrm{TU} \rightarrow\left[\mathrm{Cu}_{x}(\mathrm{TU})_{x+y}\right]^{x+}$

Reaction (5) applies to different stable complex species whose stoichiometry depends on the concentration ratio between $\mathrm{Cu}(\mathrm{II})$ ions and $\mathrm{TU}$ in solution. The structure and stoichiometry of sulphate salts containing one of the $\left[\mathrm{Cu}_{4} \mathrm{TU}_{7}\right]^{4+},\left[\mathrm{Cu}_{4} \mathrm{TU}_{6}\right]^{4+},\left[\mathrm{Cu}_{2} \mathrm{TU}_{5}\right]^{2+}$ or $\left[\mathrm{Cu}_{2} \mathrm{TU}_{6}\right]^{2+}$ cations were recently determined by X-ray diffractometry $[14,15]$. The formation of these complexes has been explained from the typical chemical behaviour of the thiol form of thioamides, such as TU, which permits its oxidation to disulphide. In contrast to $\mathrm{N}$-substituted derivatives that are capable of complexing metal ions in their higher oxidation state such as $\mathrm{Cu}(\mathrm{II})$, because thiol-thione tautomerism is impeded, unsubstituted thioureas form only $\mathrm{Cu}(\mathrm{I})$ complexes [48].

From the standpoint of surface chemistry, during the electrodeposition of $\mathrm{Cu}(\mathrm{II})$ it has been proposed that $\mathrm{Cu}(\mathrm{I})$ ions form adsorbed complexes with $\mathrm{TU}$ at low current densities, whereas at high densities adsorption saturation with respect to $\mathrm{TU}$ is attained, then the discharge from $\mathrm{Cu}(\mathrm{II})$ aquo complex ions takes place [47].

Finally, in $\mathrm{Cu}(\mathrm{II})$-containing solutions neither FDS nor its decomposition products form those complex species that are characterised by an absorption band at $340 \mathrm{~nm}$ [13].

\subsection{System copper-TU adsorbates}

Radiotracer and electroreflectance (ER) data [16] of copper in aqueous TU-containing $1.5 \mathrm{M}$ sulphuric acid have shown a strong chemisorptive interaction of TU with copper without sulfur formation, as the counting of ${ }^{14} \mathrm{C}$ did not decrease. For $c_{\mathrm{TU}}<1 \mathrm{mM}$, the coverage of copper by TU increases slowly to reach a monolayer coverage as the potential approaches $0.2 \mathrm{~V}$ [16]. Conversely, for $c_{\mathrm{TU}}>1 \mathrm{mM}$, the surface coverage increases sharply with $E$ up to the multilayer level, although no adsorption equilibrium is attained for $E>-0.2 \mathrm{~V}$. Seemingly, TU undergoes polycondensation to polythiourets, as concluded from the linear increase in polymer concentration with time and the reversibility of the polymerisation process [16]. The adsorption of TU on copper from aqueous TU-containing $1 \mathrm{M}$ perchloric acid attains a maximum coverage at ca. $0.1 \mathrm{~V}$ [24].

As has been concluded from SERS data, TU adsorbs onto copper via the $\mathrm{S}$ atom [25]. This is favoured by the $\mathrm{H}_{2} \mathrm{NHNC}-\mathrm{SH}$ tautomeric form of TU [19]. The shift of the corresponding spectral bands due to the presence of TU species agrees with the formation of $\mathrm{Cu}(\mathrm{I})$ complexes involving TU and sulphate at the electrode surface [25].

In situ IR spectra of the copper-TU adsorbate/solution interface taken at potentials negative to $E_{\text {oc }}$ provided evidence of the partial desorption of $\mathrm{TU}$ from copper in $0.5 \mathrm{M}$ sulphuric acid. Changes exhibited by $\mathrm{N}-\mathrm{C}-\mathrm{N}$ bipolar symmetric vibrational bands were assigned to either a protonation of the $\mathrm{S}$ atom or to adsorption of TU via the $\mathrm{S}$ atom [26].

Finally, in the potential range where the electrodissolution of copper takes place, TU and FDS decompose yielding adsorbed sulphur-containing and other residual species that promote the localised electrodissolution of copper [18].

\subsection{Open circuit potential of copper electrodes in aqueous 0.5 M sulphuric acid}

\subsubsection{Thiourea-containing solutions}

For copper in aqueous $0.1 \mathrm{mM} \leq c_{\mathrm{TU}} \leq 10 \mathrm{mM}+0.5$ $\mathrm{M}$ sulphuric acid, the slope of the $E_{\mathrm{oc}}$ vs $\log c_{\mathrm{TU}}$ plot (Fig. 1a) is close to $-0.118 \mathrm{~V} \mathrm{decade}^{-1}$. This linear portion extends over the range $-0.16 \mathrm{~V} \leq E_{\mathrm{oc}} \leq 0.08$ $\mathrm{V}$, i.e. the potential window where the pair of peaks 
$I_{a} / I_{c}$ is observed (Fig. 2). This coincidence, however, cannot be explained by reaction (3), as the latter would predict the slope $-0.059 \mathrm{~V} \mathrm{decade}^{-1}$. Therefore, it seems reasonable to relate the behaviour of these values of $E_{\mathrm{oc}}$ to the presence of $\mathrm{Cu}(\mathrm{I})-\mathrm{TU}$ complexes.

Thus, considering the simplest equilibrium reaction, in which copper and TU are involved

$\mathrm{Cu}\left[\mathrm{TU}_{2}^{+}(\mathrm{aq})+\mathrm{e}^{-} \rightleftharpoons \mathrm{Cu}(\mathrm{s})+2 \mathrm{TU}\right.$ (sol)

the corresponding Nernst equation, at $298 \mathrm{~K}$, is

$E=E^{0^{\prime}}-0.059 \log \frac{[\mathrm{TU}]^{2}}{\left[\mathrm{Cu}(\mathrm{TU})_{2}\right]^{+}}$

where $E^{0^{\prime}}$ stands for the standard potential including activity coefficients, brackets refer to the concentration of reactants and products, and $a_{\mathrm{Cu}}=1$.

Eq. (7) predicts an $E_{\mathrm{oc}}$ vs $\log c_{\mathrm{TU}}$ linear dependence with the slope $-0.118 \mathrm{~V}$ with respect to $c_{\mathrm{TU}}$ and a linear $E_{\mathrm{oc}} \mathrm{vs} \log c_{\left[\mathrm{Cu}(\mathrm{TU})_{2}\right]+}$ plot with the slope 0.059 $\mathrm{V}$ decade $^{-1}$, in agreement with experimental data for $c_{\mathrm{TU}}<10 \mathrm{mM}$ (Fig. 1). The structure of the $\mathrm{Cu}(\mathrm{TU})_{2}^{+}$ complex as the chloride salt has been determined by X-ray diffractometry [49].

On the other hand, for $c_{\mathrm{TU}}>10 \mathrm{mM}$, the increase in $\Delta E_{\mathrm{oc}} / \Delta \log c_{\mathrm{TU}}$ to $-0.180 \mathrm{~V}$ decade ${ }^{-1}$ can be assigned to an increase in the number of TU molecules participating in a complex reaction such as Reaction (6). In fact, the presence of $\mathrm{Cu}(\mathrm{I})-\mathrm{TU}$ complexes of different stoichiometries offers an alternative for interpreting the $E_{\mathrm{oc}}$ vs $\log c_{\mathrm{TU}}$ plots [15]. For instance, considering that the $\left[\mathrm{Cu}_{2} \mathrm{TU}_{6}\right]^{2+}$ species is formed from solutions containing $\mathrm{Cu}(\mathrm{II})$ ions and an excess of $\mathrm{TU}\left(c_{\mathrm{TU}} \gg 10 \mathrm{mM}\right)$ [15], then the following reaction:

$\left[\mathrm{Cu}_{2}(\mathrm{TU})_{6}\right]_{\text {sol }}^{2+}+2 \mathrm{e}^{-} \rightleftharpoons 2 \mathrm{Cu}+6 \mathrm{TU}$

whose equilibrium potential is given by the equation

$E=E^{0^{\prime}}-\frac{0.059}{2} \log \frac{[\mathrm{TU}]^{6}}{\left[\mathrm{Cu}_{2}(\mathrm{TU})_{6}\right]^{2+}}$

accounts for the slope $-0.180 \mathrm{~V}$ derived from the linear $E$ vs $\log c_{\mathrm{TU}}$ plot (Fig. 1). It should be pointed out that the $\left[\mathrm{Cu}_{2} \mathrm{TU}_{6}\right]^{2+}$ species has also been identified and its structure determined by X-ray diffractometry [15].

\subsection{2. $T U$ - and copper sulphate-containing solutions}

When $\mathrm{Cu}(\mathrm{II})$ ions are added to $x \mathrm{mM} \mathrm{TU}+0.5 \mathrm{M}$ sulphuric acid solution and the condition $c_{\mathrm{CuSO}_{4}} \ll c_{\mathrm{TU}}$ is fulfilled, $\mathrm{Cu}$ (II) ions react with $\mathrm{TU}$ according to reaction (4), i.e. almost all $\mathrm{Cu}$ (II) ions are reduced to $\mathrm{Cu}(\mathrm{I})-\mathrm{TU}$ complexes. Assuming that the simple stoichiometry shown in Eq. (6) is valid and that $c_{\mathrm{TU}}=$ $c_{\mathrm{CuSO}_{4}}$, a linear $E_{\mathrm{oc}}$ vs $\log c_{\mathrm{CuSO}_{4}}$ plot with the slope $-0.059 \mathrm{~V} \mathrm{decade}^{-1}$ is obtained, in agreement with the slope observed from this type of solution (Fig. 1b).

\subsubsection{FDS-containing solutions}

The value of $E_{\mathrm{oc}}$ in $1 \mathrm{mM} \mathrm{TU}+x \mathrm{mM}$ FDS + aqueous $0.5 \mathrm{M}$ sulphuric acid remains constant irrespective of $c_{\mathrm{FDS}}$. Otherwise, in the absence of TU, the value $\Delta E_{\mathrm{oc}} / \Delta \log c_{\mathrm{FDS}}=-0.059 \mathrm{~V} \mathrm{decade}^{-1}$ is consistent with the equilibrium

$[\mathrm{Cu}(\mathrm{FDS})]^{+}+\mathrm{e}^{-} \rightleftharpoons \mathrm{Cu}+\mathrm{FDS}$

the Nernst equation being

$E=E^{0^{\prime}}-0.059 \log \frac{[\mathrm{FDS}]}{\left[\mathrm{Cu}(\mathrm{FDS})^{+}\right]}$

It should be noted that reactions reactions (6), (8) and (10) do not depend on the solution $\mathrm{pH}$, in agreement with the experimental data, at least for the range $0.9 \leq \mathrm{pH} \leq 5.8$.

\subsection{Kinetics and possible reaction pathway for copper electro-oxidation in TU-containing sulphuric acid solutions}

The first stage for the electro-oxidation of $\mathrm{TU}$ on copper involves the adsorption of TU on the metal via its tautomeric form [19], TU-adsorbates being produced at either constant potential or open circuit condition, reaching a surface coverage of ca. $80 \%$ after $300 \mathrm{~s}$, as concluded from thallium upd experiments (Fig. 6). The TU adsorption process presumably involves a partial charge transfer similar to that found for the adsorption of thiols on gold [50]

$\mathrm{Cu}+\mathrm{TU} \rightarrow\left[\mathrm{Cu}\left(\mathrm{TU}^{*}\right)_{\mathrm{ad}}\right]^{\delta+}+\mathrm{H}^{+}+(\delta+1) \mathrm{e}^{-}$

yielding a fractional monolayer coverage by $\mathrm{TU}^{*}$, where $\mathrm{TU}^{*}$ stands for a deprotonated $\mathrm{TU}$ molecule. This reaction is supported by recent quantum calculations that showed that the adsorption energy for the $\mathrm{S}-\mathrm{H}$ form of $\mathrm{TU}$ is much lower than that obtained for the $=\mathrm{C}=\mathrm{S}$ form [21].

As was concluded previously $[12,13,44,46,51]$, in the range $0.14 \mathrm{~V} \leq E \leq 0.17 \mathrm{~V}$, Reaction (12) favours the electrodissolution of copper to $\mathrm{Cu}(\mathrm{I})$ according to a reaction that can be formally written as

$\left[\mathrm{Cu}\left(\mathrm{TU}^{*}\right)_{\mathrm{ad}}\right]^{\delta+} \rightleftharpoons[\mathrm{Cu}(\mathrm{TU})]_{\mathrm{aq}}^{+}+(1-\delta) \mathrm{e}^{-}$

Then, $\mathrm{Cu}\left(\mathrm{TU}^{*}\right)_{\mathrm{ad}}$ can be considered as a precursor of copper electrodissolution through $[\mathrm{Cu}(\mathrm{TU})]_{\mathrm{aq}}^{+}$species yielding soluble $\mathrm{Cu}(\mathrm{I})$ complex ions in solution.

Otherwise, in the potential range $0.14 \mathrm{~V} \leq E \leq 0.17 \mathrm{~V}$ (Fig. 2) the electro-oxidation of TU on copper yields soluble FDS (peak $I_{a}$ ) from either the electro-oxidation of adsorbed TU or the radical ion $\mathrm{TU}^{+} \cdot$ in solution [52], whereas the electroreduction of soluble FDS to TU is related to peak $I_{a}$. In principle, the linear dependence of both peaks $\mathrm{I}_{\mathrm{a}}$ and $\mathrm{I}_{\mathrm{c}}$ on $v^{1 / 2}$ at a constant $c_{\mathrm{TU}}$ and the difference $\Delta E_{\mathrm{p}}=E_{\mathrm{p}, \mathrm{a}}-E_{\mathrm{p}, \mathrm{c}}=0.2 \mathrm{~V}$, a figure greater than $0.059 \mathrm{~V}$, indicates that these reactions involve the 
diffusion of reactants from the bulk of the solution to the electrode surface with a considerable degree of irreversibility [23], as is discussed later.

The soluble FDS produced by the electro-oxidation of TU can also be adsorbed on the copper electrode. The formation of adsorbed FDS has been observed on $\mathrm{Au}(111)$ by in situ STM imaging [17], although the interaction of FDS with metal surfaces is expected to be weaker than that of $\mathrm{TU}$, as has been earlier concluded from the comparative adsorption of thiols and disulphides on gold [53,54]. The formation of FDS also assists the electrodissolution of copper presumably through the formation of an intermediate such as $\mathrm{Cu}(\mathrm{FDS})_{\mathrm{ad}}$ [18]. A possible reaction pathway for these processes has been discussed recently [18].

The hump $\mathrm{I}_{1}^{\mathrm{D}}$ and peaks $\mathrm{I}_{2}^{\mathrm{D}}$, observed at the RDE for $E_{\mathrm{D}} \approx 0.2 \mathrm{~V}$ (Fig. 7), are related to a surface adsorption process involving FDS superimposed onto the mass transport controlled TU electro-oxidation and copper electrodissolution currents. The contribution of this surface process is influenced by both $c_{\mathrm{TU}}$ and $v$, i.e. as $c_{\mathrm{TU}}$ is increased or $v$ is decreased, the current contributions $\mathrm{I}_{1}^{\mathrm{D}}$ and $\mathrm{I}_{2}^{\mathrm{D}}$ tend to disappear (Fig. 8). This would mean that surface species related to these current contributions are gradually suppressed by increasing either $c_{\mathrm{TU}}$ or the reaction time (decreasing $v$ ), i.e. under favourable conditions for a chemical reaction between surface species and TU.

On the other hand, the potentials at which hump $I_{1}^{D}$ and peak $I_{2}^{D}$ in the RRDE are observed, are close to the $\mathrm{Cu}(\mathrm{II})-\mathrm{Cu}(\mathrm{I})$ equilibrium potential [11]. The anodic charges related to these current contributions are $0.042 \mathrm{mC} \mathrm{cm}^{-2}$ for hump I $\mathrm{I}_{1}^{\mathrm{D}}$ and $0.092 \mathrm{mC} \mathrm{cm}^{-2}$ for peak $I_{2}^{D}$. Hump $I_{1}^{D}$ can be assigned to the formation of the insoluble polymer-like film from adsorbed TU-species [31]. This film hinders the formation of soluble anodic products, as seen by the RRDE response (Fig. 7) and favours the formation of soluble $\mathrm{Cu}(\mathrm{II})$ ions at the reaction interface, as seen from the enhancement of cathodic current at the ring, and the appearance of peak $I_{2}^{\mathrm{D}}$ at the disk, which corresponds to the electroreduction of a part of $\mathrm{Cu}$ (II) remaining at the reaction interface which is captured at relatively high $v$ and low $c_{\mathrm{TU}}$.

It should be noted that the contribution of sulphide species to the appearance of peaks $\mathrm{I}_{1}^{\mathrm{D}}$ and $\mathrm{I}_{2}^{\mathrm{D}}$ was ruled out because the addition of small amounts of sodium sulphide to the TU-containing solutions had no significant effect on the voltammetric runs.

Finally, for $E>0.2 \mathrm{~V}$, FDS is oxidised to S- and CN-containing species [18], a process that eventually changes the nature of products blocking the copper surface.

\subsection{Kinetic parameters for $T U$ electrochemical reactions at copper electrodes in aqueous \\ TU-containing $0.5 \mathrm{M}$ sulphuric acid}

At constant $c_{\mathrm{TU}}$, the dependence of peak $\mathrm{I}_{\mathrm{a}}$ on $v^{1 / 2}$ deviates from linearity on increasing $v$ (Fig. 4). This behaviour can be interpreted assuming a partial blockage of the anode surface which interferes with the mass transfer process. This interference can be accounted for by considering an effective electrode area $\left(A_{\mathrm{cf}}\right)$, which can be expressed as $A_{\mathrm{cf}}=A_{0}(1-\theta)$, where $A_{0}$ is the geometric electrode area, and $\theta$ is a $c_{\mathrm{TU}^{-}}$and potentialdependent surface coverage by adsorbates. Values of $\theta$ can be obtained from either data shown in Fig. (5) or from the deviation of the slopes of the plots of $\Delta I_{\mathrm{L}}$ / $\Delta \omega^{1 / 2}$ with $c_{\mathrm{TU}}$ (Fig. 10, inset). Accordingly, TU electro-oxidation on copper in aqueous sulphuric acid can be described as an electrochemical reaction under intermediate kinetics on an electrode surface which is progressively blocked as $c_{\mathrm{TU}}$ is increased. This also makes the reverse reaction more irreversible as manifested by the hysteresis loop in the RDE polarisation curves (Fig. 8 ), and the $\Delta E_{\mathrm{p}} \simeq 0.2 \mathrm{~V}$ in the voltammograms.

As far as TU adsorbates on copper is concerned, the $\theta$ vs $\log c_{\mathrm{TU}}$ dependence resulting from different experiments (Figs. 5 and 10, inset) suggests that the adsorption is influenced by the surface heterogeneity as predicted by the Temkin adsorption model [55].

At constant $c_{\mathrm{TU}}$, the dependence of the quasi-steady limiting current $\left(I_{\mathrm{L}}\right)$ on $\omega^{1 / 2}$ fulfils the Levich equation

$I_{\mathrm{L}}=0.620 n F A_{\mathrm{cf}} D_{\mathrm{i}}^{2 / 3} v^{-1 / 6} c_{\mathrm{TU}} \omega^{1 / 2}$

where $n$ is the number of electrons per reactant molecule, $F$ is the Faraday constant and $v$ is the kinematic viscosity of the solution. Eq. (14) is fulfilled over the whole range of $c_{\mathrm{TU}}$ used in the present work (Fig. 9). Considering $A_{\mathrm{cf}}=A_{0}(1-\theta)$, values of $\theta$ shown in Fig. 10 (inset), $n=1$ and $v \simeq 0.01 \mathrm{~cm}^{2} \mathrm{~s}^{-1}$, it results in $D_{\mathrm{i}}=9 \pm 0.1 \times 10^{-6} \mathrm{~cm}^{2} \mathrm{~s}^{-1}$ for the different values of $c_{\mathrm{TU}}$. This figure for $D_{\mathrm{i}}$ agrees with that recently reported for TU electro-oxidation on platinum electrodes [38] and with the values $1.2 \times 10^{-5}$ and $8.9 \times$ $10^{-6} \mathrm{~cm}^{2} \mathrm{~s}^{-1}$ that have been reported for $\mathrm{TU}$ on copper electrodes in nitric [56] and sulphuric acid [57] solutions, respectively.

The linearity of the Koutecky-Levich-like plots in the mixed kinetic regime (Fig. 11) is consistent with a first-order electrochemical reaction [23] as in the case of the electro-oxidation of TU on platinum electrodes [38]. The overall current involves the contribution of $I_{\mathrm{k}}$, the true kinetic current that can be derived from these plots at different potentials. Values of $I_{\mathrm{k}}$ fulfil a Tafel relationship with the slope $b_{\mathrm{T}} \simeq 0.118 \mathrm{~V}$ decade $^{-1}$ (Fig. 12), i.e. a figure which is consistent with the first single electron transfer as the rate determining step [58].

On the other hand, $I_{\mathrm{k}}$ can be expressed as 
$I_{\mathrm{k}}=n F A_{\mathrm{cf}} c_{\mathrm{TU}} k^{0} \exp (\alpha n F E / R T)$

where $k^{0}$ is the standard heterogeneous rate constant and $\alpha$ is the transfer coefficient assisting the reaction in the positive direction.

Therefore, from the $\log I_{\mathrm{k}}$ vs $E$ plots, for the different $c_{\mathrm{TU}}$, we find that in $k^{0}=5 \pm 3 \times 10^{-3} \mathrm{~cm} \mathrm{~s}^{-1}$ and $\alpha=0.55 \pm 0.03$. The value of $k^{0}$ is about one order of magnitude higher than that found for platinum electrodes [38], in agreement with the lower value of $\Delta E_{\mathrm{p}}$ resulting from the voltammograms (Fig. 2) as compared to that recorded for platinum (ca. $0.45 \mathrm{~V})$. It should be noted that the value of $k^{0}$ does not have a universal meaning due to the complex characteristics of the reacting surface.

\section{Conclusions}

- The dependence of the open circuit potential of copper in aqueous TU-containing $0.5 \mathrm{M}$ sulphuric acid on the concentration of TU can be explained by the formation of several $\mathrm{TU}-\mathrm{Cu}(\mathrm{I})$ complexes of different stoichiometries. The value of $E_{\mathrm{oc}}$ depends neither on the $\mathrm{pH}(0.9 \leq \mathrm{pH} \leq 5.8)$ nor on the FDS concentration $\left(0.1 \mathrm{mM} \leq c_{\mathrm{FDS}} \leq 10 \mathrm{mM}\right)$ in solution.

- In the low potential range, the electro-oxidation of TU on copper yields FDS and $\mathrm{Cu}(\mathrm{I})$ complex ions, these reactions being accompanied by the formation of TU and TU derivatives on the copper surface, which act as precursors of copper electrodissolution.

- Depending on the potential range, adsorbates are formed either directly from a strong TU-copper interaction or from a weaker FDS-copper interaction. Insoluble polymer-like $\mathrm{TU}-\mathrm{Cu}(\mathrm{I})$ layers are formed.

- Kinetic data can be interpreted as a first-order single electron transfer under a mixed regime. The Levich equation is obeyed provided that a correction term for the effective electrode area is considered. This correction can be made from the analysis of either voltammetric or RDE data.

- A complex reaction pathway, which has been proposed previously, accounts for the electrochemical behaviour of TU and FDS on copper electrodes in aqueous TU-containing sulphuric acid. It involves the participation of different adsorbates and $\mathrm{Cu}(\mathrm{I})$ complex ions in solution. These conclusions are useful to understand the effect of sulphur-containing additives on metal electrode reactions.

\section{Acknowledgements}

This work was supported financially by the Consejo Nacional de Investigaciones Científicas y Técnicas
(CONICET) (PIP 4376) and Agencia Nacional de Promoción Científica y Tecnológica (PICT 98 06-03251) of Argentina and the Comisión de Investigaciones Científicas de la Provincia de Buenos Aires (CIC). B.I.W. thanks the Third World Academy of Science (TWAS) and CONICET for the fellowship granted.

\section{References}

[1] D. Suarez, F. Olson, J. Appl. Electrochem. 22 (1992) 1002.

[2] E.E. Farndon, F.C. Walsh, S.A. Campbell, J. Appl. Electrochem. 25 (1995) 574.

[3] V.S. Martín, S. Sanllorente, S. Palmiero, Electrochim. Acta 44 (1998) 579

[4] A.C. Makrides, N. Hackerman, Ind. Engng Chem. 47 (1955) 1773.

[5] M.J. Jannssen, Spectrochim. Acta 17 (1961) 474

[6] T.K. Ross, D.H. Jones, J. Appl. Chem. 12 (1962) 314.

[7] K.C. Pillai, R. Narayan, J. Electrochem. Soc. 125 (1978) 1393.

[8] B.C. Ateya, B.E. El-Anadouli, F.M. El-Nizamy, Corros. Sci. 24 (1984) 497.

[9] R. Agarwal, T.K.G. Namboodhiri, Corros. Sci. 30 (1990) 37.

[10] Z.D. Stankovic, M. Vukovic, Electrochim. Acta 41 (1996) 2529.

[11] U. Bertocci, D.R. Turner, in: A.J. Bard (Ed.), Encyclopedia of Electrochemistry of the Elements, vol. II, Marcel Dekker, New York, 1974 (Ch. VI).

[12] A. Szymaszek, J. Biernat, L. Pajdowski, Electrochim. Acta 22 (1977) 359.

[13] P. Javet, H.E. Hintermann, Electrochim. Acta 14 (1969) 527.

[14] R.C. Bott, G.A. Bowmaker, C.A. Davis, G.A. Hope, B.E. Jones, Inorg. Chem. 37 (1998) 651.

[15] O. Piro, R.C.V. Piatti, A.E. Bolzán, R.C. Salvarezza, A.Y. Arvia, Acta Crystallogr. B 56 (2000) 493.

[16] G.V. Korshin, A. Petukhov, A.M. Kuznetsov, Y.M. Vyzhimov, Elektrokhimiya 27 (1991) 275.

[17] O. Azzaroni, B. Blum, R.C. Salvarezza, A.J. Arvia, J. Phys. Chem. B Lett. 104 (2000) 1395.

[18] A.E. Bolzán, A.S.M.A. Haseeb, P.L. Schilardi, R.C.V. Piatti, R.C. Salvarezza, A.J. Arvia, J. Electroanal. Chem. (2001), in press.

[19] E.E. Reid, Organic Chemistry of Bivalent Sulfur, vol. 5, Chemical Publishing, 1963.

[20] P. Shigolev, Electrolytic and Chemical Polishing of Metals, Freund Publishing House, Tel Aviv, 1974.

[21] P. Carro, private communication.

[22] J. Biernat, A. Szymaszek, Bull. Acad. Polon. Sci., Ser. Sci. Chim. 24 (1976) 133.

[23] A.J. Bard, L.R. Faulkner, Electrochemical Methods, Wiley, New York, 1980.

[24] G. Horanyi, E.M. Rizmayer, P. Joó, J. Electroanal. Chem. 149 (1983) 221.

[25] C.M. Brown, C.A. Hope, D.P. Schweinsberg, P.M. Fredericks, J. Electroanal. Chem. 380 (1995) 161.

[26] D. Papapanayiotou, R.N. Nuzzo, R.C. Alkire, J. Electrochem. Soc. 145 (1998) 3366.

[27] D.M. Kolb, in: H. Gerischer, G. Tobias (Eds.), Advances in Electrochemistry and Electrochemical Engineering, vol. 11, Wiley, New York, 1978.

[28] R.R. Adzic, Israel J. Chem. 18 (1979) 166.

[29] D.A. Berg, D.S. Nadezdhim, R.G. Barradas, J. Electroanal. Chem. 355 (1993) 165.

[30] A. Hernández Creus, R.M. Souto, S. González, M.M. Laz, R.C. Salvarezza, A.J. Arvia, Appl. Surf. Sci. 81 (1994) 387.

[31] A.S.M.A. Haseeb, P.L. Schilardi, R.C.V. Piatti, A.E. Bolzán, R.C. Salvarezza, A.J. Arvia, J. Electroanal. Chem. 500 (2001) $533-542$. 
[32] M. Hoffmann, J.O. Edwards, Inorg. Chem. 16 (1977) 3333.

[33] G. Davies, Inorg. Chem. 11 (1972) 2489.

[34] V.P. Vasil'ev, V.I. Shorokhova, N.K. Grechina, L.V. Katrovtseva, Russ. J. Inorg. Chem. 23 (1978) 1274.

[35] J.H. Barber, B.E. Conway, J. Chem. Soc. Faraday Trans. 92 (1996) 3709.

[36] D.R. Turner, G.R. Johnson, J. Electrochem. Soc. 109 (1962) 382.

[37] H. Marshall, Proc. R. Soc. Edinburgh 24 (1902) 233.

[38] A.E. Bolzán, I.B. Wakenge, R.C. Salvarezza, A.J. Arvia, J. Electroanal. Chem. 475 (1999) 181.

[39] M. Yan, K. Liu, Z. Jiang, J. Electroanal. Chem. 408 (1996) 225.

[40] D.S. Tarbell, in: N. Kharasch (Ed.), Organic Sulfur Compounds, vol. 1, Pergamon, New York, 1961 (Ch. X).

[41] P.W. Preisler, L. Berger, J. Am. Chem. Soc. 69 (1947) 322.

[42] E.A. Werner, J. Chem. Soc. 101 (1912) 2166.

[43] F. Kurzer, P.M. Sanderson, J. Chem. Soc. (1959) 1058.

[44] H.M. Ratajczak, L. Pajdowski, Inorg. Nucl. Chem. 36 (1974) 431.

[45] P. Schilardi, A.E. Bolzán, R.C.V. Piatti, O.E. Piro, C. Gutiérrez, R.C. Salvarezza, A.J. Arvia, in preparation.

[46] E.I. Onstott, H.A. Laitinen, J. Am. Chem. Soc. 72 (1950) 4724.
[47] N. Zukauskaite, A. Malinauskas, Electrokhimiya 24 (1988) 1567.

[48] P. Caston, J. Jaud, N.P. Johnson, R. Soules, J. Am. Chem. Soc. 107 (1985) 5011.

[49] W.A. Spofford, E.L. Hamma, Acta Crystallogr. B 26 (1970) 1474.

[50] D.W. Hatchett, K.J. Stevenson, W.B. Lacy, J.M. Harris, H.S. White, J. Am. Chem. Soc. 119 (1997) 6596.

[51] F.A. Cotton, G. Wilkinson, Advanced Inorganic Chemistry, 4th ed., Wiley, Chichester, 1980.

[52] S.J.J. Reddy, V.N. Krishnan, J. Electroanal. Chem. 27 (1970) 473.

[53] L.-H. Wan, Y. Hara, H. Noda, M. Osawa, J. Phys. Chem. B 102 (1998) 5943.

[54] T.Y. Leung, M.C. Gerstenberg, D.J. Lavrich, G. Scoles, F. Schreiber, G.E. Porter, Langmuir 16 (2000) 549.

[55] A.W. Adamson, Physical Chemistry of Surfaces, Wiley, New York, 1982.

[56] J. Kirchenerovâ, W.C. Purdy, Anal. Chim. Acta 123 (1981) 83.

[57] M. Alodan, W. Smyrl, Electrochim. Acta 44 (1998) 299.

[58] B.E. Conway, Theory and Principles of Electrode Kinetics, Ronald Press, New York, 1965. 